\title{
Impact of Implementing an Educational Program Regarding Care of Nasogastric Tube Feeding on Nurses' Knowledge and Performance
}

\author{
تأثير برنامج تعليمي عن التظذيه بواسطة الأنبوب المعدي علي معلومات واداء الممرضات \\ Dr. Nagla Hamdi Kamal Khalil El-Meanawi, \\ Medical-Surgical Nursing, Faculty of Nursing, Alexandria University,Egypt
}

\begin{abstract}
:
Introduction: Enteral nutrition is the preferred feeding method for those patients with normal functioning gastrointestinal tracts ${ }^{(5)}$ as comatose patients, patients breathing with the assistance of a mechanical ventilator and premature infants. Patient outcomes are affected by nursing care quality. Thus, improvements in patient safety can be achieved by improving nurse performance. Major attention must be focused on nurse's knowledge and performance regarding nasogastric tube because nurses have the major responsibility for providing patients with their essential nutrients without causing complications.

Aims: This study carried out to evaluate the effectiveness of an educational program regarding care of nasogastric tube feeding on nurse's knowledge and performance, and to assess the relationship between nurses' knowledge and performance regarding to NGT feeding.

Method: 175 registered nurses were working in the medical, and surgical words, at King Fahed Hospital who caring for patients with nasogastric tube feeding.

Tools: two tools: Tool I: Nurses' Knowledge Questionnaire Sheet. Tool II: Nasogastric Tube Feeding Observational Check List:

Results: findings revealed that there is a highly significant difference between pre and post evaluations scores in relation to nurse's knowledge and performance after completion of the educational program.

Conclusion: based on research findings, that participation in the educational program for nasogastric tube feeding made differences in nurse's knowledge and performance.
\end{abstract}

Keywords: Nasogastric tube - nurses' knowledge-nurses Performance.

\section{Introduction}

Nutrition is the science of food and its relationship to health. It is concerned primarily with the part played by nutrients in body growth, development and maintains. For every human being eating food is an enjoyment, which is the Allah gift. The person consumes food orally with proper nutrition; health will be maintained optimally. In these following conditions person is unable to take oral feeding; dysphagia, pharyngitis, esophagitis, bulbar palsy, burns, pancreatitis and postoperative Patients. Patients who are unable to swallow sufficient nutrients like, those who are suffering from: cerebral vascular accidents, progressive oral and pharyngeal tumors, degenerative neurological disorders, upper gastrointestinal surgeries and head-neck surgery.

In these conditions, it is very necessary to maintain or improve their nutritional status. Nasogastric tube feeding is a common method of maintaining or improving nutritional status in patients who are unable to take sufficient nutrition orally. Patients in the hospital, as well as home care sittings, often require nutritional supplementation with enteral feeding. Enteral feeding can be administered via nasogastric, nasoduodenal, and nasojejunal. ${ }^{(2)}$

Nasogastric tube is a thin soft tube that delivers nutrients from the nasal route into the stomach via a feeding tube. It used to administer nutrition to patient with inability to ingest adequate nutrients slowly by mouth. ${ }^{(3)}$ Nasogastric tube feeding may be accompanied by complications as, gagging or vomiting / nausea , tissue trauma / irritation along the nasal, oropharngeal or upper gastrointestinal $\operatorname{tract}^{(4)}$, pain diarrhea , gas/bloating /cramping. Constipation and aspiration pneumonia ${ }^{(5)}$. It is important for the nurses to improve their knowledge and performance to prevent these complications.

Enteral nutrition is the preferred feeding method for those patients with normal functioning gastrointestinal tracts ${ }^{(5)}$ as comatose patients, patients breathing with the assistance of a mechanical ventilator and premature infants. ${ }^{(6)}$ Insertion of a nasogastric tube for unstable patient, Irrigate tube. After tube placement verified, administer bolus $\backslash$ medications or continuous enteral feeding. Evaluate nutritional status, monitor for 
complications related to tubes and enteral feedings, educate patient about home internal feeding tube care. ${ }^{(7)}$ All are important nursing roles for caring patients with nasogastric tube.

To maintain patency, it is best to flush feeding tubes with 30 to $60 \mathrm{~mL}$ of water immediately before and after administering a feeding or medications, every 4 hours if the patient is being continuously fed, and after refeeding the gastric residual. Clearing an obstruction occasionally, it is possible to clear the tube with a solution. When an obstruction cannot be cleared, the tube is removed and another inserted rather than compromising nutrition by the delay. ${ }^{(8,9)}$

Knowledge is the fact or state of knowing. It's the awareness of fact or have knowing enough information about subject. ${ }^{(10) .}$ Nursing knowledge is a complex question, to answer these questions the nurse must have enough information, theoretical from lecture, course, articles, books or practical from experience from work in hospital or workshop. Nurses use a wide range of theoretical and practical knowledge in their work. They need a considerable amount of new knowledge to provide appropriate level of care for patients. ${ }^{(11)}$

Patient outcomes are affected by nursing care quality. Thus, improvements in patient safety can be achieved by improving nurse performance. ${ }^{(12)}$ Nursing performance is determined by the needs of patients and reflects an integration of knowledge, skills and experience. ${ }^{(13)}$ Understanding the basic concept in nursing practice, help in enhance performance. ${ }^{(14)}$ Nurses should be alert about tube size selection, assessment of tube position, methods of securing tube or method of feeding ${ }^{(11)}$, providing correct patients position, checking the patency of tube, checking the food content (Liquid foods are used), assessing the bowel sounds, which are important components to minimize the risks of NG tube related complications and to provide optimal patient safety and comfort. ${ }^{(15)}$

Major attention must be focused on nurse's knowledge and performance regarding nasogastric tube because nurses have the major responsibility for providing patients with their essential nutrients without causing complications. As well as continuous education and training of all hospital staff is essential to increase their awareness about important nursing procedures as nasogastric tube.

\section{Aims of The Study}

To assess nurses' knowledge and practices about NGT feeding.

To evaluate the effectiveness of an educational program regarding NGT feeding on the nurse's knowledge and practice.

To assess the relationship between nurses's knowledge and performance regarding to NGT feeding.

\section{Design:}

\section{Materials And Methods}

Pre-post study design was used. Quasi experimental, without control study.

Setting: The present study was conducted in surgical and medical wards -King Fahed Hospital - Al Madinah El- Menawarah.

\section{Subjects:}

The subjects of the present study were selected as a convenience sampling. They consisted of 175 nurses meet inclusion criteria to join the study. The inclusion criteria for nurses were: both sexes ages were from 18 to 50 years. Nurses who didn't receive any related educational program. 175 registered nurses were working in the surgical words (25) and medical wards (120) at king fahed hospital who is assigned for caring for patients with a nasogastric tube feeding. Pre-Test Self-report questionnaires Knowledge the number become: 145, Pre-Test Observation skills and complete checklist, the number become: 104, Post - test Self-report: Knowledge: the number become $=96$ Post-Test, Observation skills and complete checklist: the number become $=78$

\section{Exclusion criteria}

1. Registered nurses who attended specialized educational program on nasogastric tube feeding.

2. Administrative nurses at these words, who didn't work directly with the patients.

\section{Tools of data collection:}

Tools:

Two tools were utilized to collect data. They were developed by the researcher. The designed tools were consists of the following:

Tool I: Nurses' Knowledge Questionnaire Sheet:

It was developed to assess nurses' knowledge about nasogastric tube care. It consists of two main Parts; Part 1: Sociodemgraphic data and questions related to the study sample. As nurse's age, educational level, and years of experience. 
Part 2: assessment of nurses' knowledge about administration of feeding via nasogastric tube. It is consists of 15 questions based on the review of literature. In the form of multiple choice and True/false ones. A correct response was scored 1 and incorrect zero. They covered knowledge pertinent to definition, indications, contraindications, and complications of NGT, formulation of NGT,.etc. A total score for the questionnaire was 15 grades. The scoring system classified as follows; scores less than $60 \%$ was considered Inadequate and the scores equal or more than $60 \%$ considered Adequate.

$\begin{array}{ll}\text { - Adequate knowledge level: } & 9-15 \text { points } \\ \text { - Inadequate knowledge level: } & 0 \text { to } 8 \text { points }\end{array}$

\section{Tool II: Nasogastric Tube Feeding Observational Check List:}

It was designed by the researcher through literature review to assess nurses' performance related preparation and care of NGT. The designed tool consists of three main parts as followed; before administration phase, during administration phase and after administration phase, assessment for complications, prevention strategies and management of complications, It was carried out three times for each nurse during feeding administration and the average mean of three observational checklists was obtained. The scoring system was distributed as follows; complete done step took two grades, incomplete one took one grade and incorrect / not done was took zero grades. A total score for the questionnaire was 27 grades .scores less than $60 \%$ was considered unsatisfactory and the scores equal or more than $60 \%$ considered satisfactory.
Satisfactory knowledge level:
17- 27 points
- Unsatisfactory knowledge level:
$0-16$ points

$(60 \%)$

These two structured sheets was administered to the subjects three times; one before the educational program (pre- test) and two times time after finishing educational program, immediately evaluation after the finishing of the program (first post- test), and the last evaluation after 3 months of the program (second posttest). The content validity of the observational checklist was achieved through a panel of experts in medical and nursing field. Based on the comments and suggestions modifications were carried out. After this it was tested for reliability on a sample of $10 \%$ of the subject's sample.

\section{Method}

A written permission to conduct the study was obtained from the administrative authorities of the hospital and the head of the surgical and medical wards. The study tools were constructed after review of literatures and were tested for its content validity by five nursing experts from different nursing and medical specialties and the necessary revisions and modification were done.

A pilot study was carried out on $10 \%$ of the study sample who were excluded from the study subjects in order to re-assess the clarity and the applicability of the tool. Any necessary modification was done after the pilot study. The researchers emphasized to the subjects that participation in the study was entirely voluntary, and the anonymity and confidentiality of responses were assured.

Tool I Nurses' knowledge questionnaire sheet was used before the program to identify nurse's knowledge.

Nurse's needs were identified by observing nursing performance before the program using the performance checklist (Tool II).

Data were collected during the period from August 2015 to October 2015 (pre- test). To establish data base.

Nurses were interviewed separately to complete the questionnaire. The time spent was 20 minutes to complete the sheet.

The instructional scheme was conducted in 3 sessions. The time of each session ranged from 30-40 minutes. During the period from November 2015 to January 2016.

Every nurse was observed for three times during different shifts for their performance before, during and after feeding patients with nasogastric tube immediately after finishing the program (first post -test).

The second post -test observation was completed after three months of the program between the months of April 2016 and May 2016. Two tools of data collection were assessed before and after the educational program.

\section{Program construction:}

\section{Content}

The program's content was selected in relation to the study aims and nurses needs. It includes:

\section{I- Theoretical Part:}

Session (1): included definition of nasogastric tube, purposes, indications for use, and the possible complications.

Session (2): included tube insertion and stabilization, auscultatory method, frequency in checking placement, tube clogging, and maintaining tube patency.

\section{Practical Part:}


Session (3): included the nursing skills in relation to care of nasogastric tube either during insertion, feeding or suctioning, as well as removal of the tube. Attention to be given in tube size selection, assessment of tube position, methods of securing tube or method of feeding which are important components to minimize the risks of NG tube related complications and to provide optimal patient safety and comfort.

\section{Teaching Methods and Aids:}

Different strategies were implemented including short lectures, role play, demonstration and redemonstration, and group discussion. Audio visual materials were used such as pictures, diagrams, and real life situations. These were used to facilitate teaching of each topic.

\section{Implementation of the program:}

The instructional scheme was conducted in 3 sessions. The time of each session ranged from 30-40 minutes.

\section{The program evaluation:}

\section{Nurses Knowledge:}

Evaluation of nurses' knowledge was categorized either as adequate when their knowledge score was more than $60 \%$ or inadequate when the score is less than $60 \%$.

\section{Nurses Performance:}

Evaluation of nurses' performance was categorized either as satisfactory when their performance score was more than $60 \%$ or unsatisfactory when the score is less than $60 \%$.

\section{Statistical analysis}

Statistical analysis was performed using the SPSS package version 19. Mean and standard deviations were used. Arithmetic mean, standers deviation, and percentage were used.

Tests were considered significant when $\mathrm{P}<0.05$.

Pre and post test score comparison.

Pre and post observational data comparison.

Person correlation analysis was used for assessment of the interrelationships among quantitative variables. To assess the relationship between scores of knowledge and performance as dependent factors, on the one hand, and various quantitative factors, as demographic characteristics of the subjects as independent factors on the other hand.

\section{Results}

Table (1): percentage distribution of Sociodemgraphic as regarding data among the study group ( $n=60$ ):

\begin{tabular}{|l|l|l|}
\hline \multicolumn{3}{|c|}{ Table 1. Demographical and Employment Data } \\
\hline & $\begin{array}{l}\text { Pre-test }(\mathbf{N}=\mathbf{1 4 5}) \\
\mathbf{N}(\mathbf{\%})\end{array}$ & $\begin{array}{l}\text { Post-test (N=96) } \\
\mathbf{N}(\%)\end{array}$ \\
\hline Age & & \\
\hline $22-28$ years & $92(63.4 \%)$ & $65(67.7 \%)$ \\
\hline $29-35$ years & $51(35.2 \%)$ & $29(30.2 \%)$ \\
\hline More than 36 years & $2(1.4 \%)$ & $2(2.1 \%)$ \\
\hline Gender & & \\
\hline Female & $111(76.6 \%)$ & $78(81.3 \%)$ \\
\hline Male & $34(23.4 \%)$ & $18(18.8 \%)$ \\
\hline Marital status & & \\
\hline Married & $90(62.1 \%)$ & $60(55.2 \%)$ \\
\hline Not married & $55(37.9 \%)$ & $36(37.5 \%)$ \\
\hline Educational level & & \\
\hline Bachelor & $143(98.6 \%)$ & $94(97.9 \%)$ \\
\hline Higher than bachelor( Master degree) & $2(1.4 \%)$ & $2(2.1 \%)$ \\
\hline Nationality & & \\
\hline Saudi & $89(61.4 \%)$ & $53(55.2 \%)$ \\
\hline Non-Saudi & $56(38.6 \%)$ & $43(44.8 \%)$ \\
\hline Workplace & & \\
\hline Medical departments & $120(82.7 \%)$ & $11(11.5 \%)$ \\
\hline Surgical departments & $25(17.2 \%)$ & $85(88.5 \%)$ \\
\hline Experience as staff (registered) nurse & & \\
\hline Less than 1 year & $16(11.0 \%)$ & $11(11.5 \%)$ \\
\hline 1-5 years & $75(51.7 \%)$ & $50(52.1 \%)$ \\
\hline 5-10 years & $45(31.0 \%)$ & $28(29.2 \%)$ \\
\hline More than 10 years & $9(6.2 \%)$ & $7(7.3 \%)$ \\
\hline Experience as staff nurse in the selected hospitals & & \\
\hline Less than 1 year & $32(22.1 \%)$ & $20(20.8 \%)$ \\
\hline 1-5 years & $75(51.7 \%)$ & $51(53.1 \%)$ \\
\hline 5-10 years & $35(24.1 \%)$ & $23(24.0 \%)$ \\
\hline & & \\
\hline
\end{tabular}


Impact of Implementing an Educational Program Regarding Care of Nasogastric Tube Feeding on ..

\begin{tabular}{|l|l|l|}
\hline More than 10 years & $2(2.1 \%)$ & $2(2.1 \%)$ \\
\hline
\end{tabular}

Table 2. Relationship between Subjects' Knowledge about Caring of Patients with Entral Feeding Tube Pre and Post Providing Educational Program

\begin{tabular}{|c|c|c|c|c|c|}
\hline \multicolumn{2}{|c|}{ Subjects' Knowledge about Entral Feeding } & $\begin{array}{l}\text { Pre-test }(\mathrm{N}=145) \\
\mathrm{N}(\%)\end{array}$ & $\begin{array}{l}\text { Post-test } \\
(\mathbf{N}=96) \\
\mathbf{N}(\%)\end{array}$ & $\mathbf{X}^{2 *}$ & p-value \\
\hline \multicolumn{6}{|c|}{$\begin{array}{l}\text { Sub-scale items that measure satisfaction of subjects' } \\
\text { knowledge about entral feeding care }\end{array}$} \\
\hline & Satisfied knowledge about definitions & $95(65.5 \%)$ & $91(94.8 \%)$ & 9.6 & 0.005 \\
\hline 2. & $\begin{array}{l}\text { Satisfied knowledge about purpose, indication } \\
\text { and advantages of enteral feeding }\end{array}$ & $64(44.1 \%)$ & $63(65.6 \%)$ & 18.7 & $<0.001$ \\
\hline 3. & Satisfied knowledge about contraindication & $102(70.2 \%)$ & $87(90.6 \%)$ & 19.9 & $<0.001$ \\
\hline 4. & $\begin{array}{l}\text { Satisfied knowledge about insertion and removal } \\
\text { of enteral feeding tubes (NGT \%) }\end{array}$ & $104(71.7 \%)$ & $84(87.5 \%)$ & 35.0 & $<0.001$ \\
\hline 5. & $\begin{array}{l}\text { Satisfied knowledge about confirming correct } \\
\text { tube position }\end{array}$ & $70(48.3 \%)$ & $79(82 \%)$ & 11.85 & $<0.001$ \\
\hline 6. & $\begin{array}{l}\text { Satisfied knowledge about types of TPN solutions } \\
\text { and Formulas' handling }\end{array}$ & $82(56.6 \%)$ & $86(89.6 \%)$ & 10.7 & 0.001 \\
\hline 7. & $\begin{array}{l}\text { Satisfied knowledge about administration of } \\
\text { enteral feeding, fluids and medications safely }\end{array}$ & $103(71.0 \%)$ & $87(90.6 \%)$ & 24.1 & $<0.001$ \\
\hline 8. & $\begin{array}{l}\text { Satisfied knowledge about care of patients with } \\
\text { enteral feeding tubes }\end{array}$ & $68(46.9 \%)$ & $62(64.6 \%)$ & 27.6 & $<0.001$ \\
\hline 9. & $\begin{array}{l}\text { Satisfied knowledge about complications and } \\
\text { disadvantages of enteral feeding }\end{array}$ & $109(75.2 \%)$ & $79(82.3 \%)$ & 29.5 & $<0.001$ \\
\hline 10. & $\begin{array}{l}\text { Satisfied knowledge about nursing process related } \\
\text { to enteral feeding }\end{array}$ & $88(60.7 \%)$ & $74(77.1 \%)$ & 35.2 & $<0.001$ \\
\hline \multicolumn{6}{|c|}{$\begin{array}{l}\text { Total Score of Nurses' knowledge about entral feeding } \\
\text { Questionnaire }\end{array}$} \\
\hline \multicolumn{2}{|c|}{$\begin{array}{l}\text { As a total, subjects had satisfied knowledge about entral } \\
\text { feeding }\end{array}$} & $90(62.0 \%)$ & $87(90.6 \%)$ & 13.9 & $<0.001$ \\
\hline \multirow{2}{*}{\multicolumn{2}{|c|}{ Total Score for knowledge about entral feeding sub-scales }} & $\begin{array}{l}\text { Pre-test } \\
\text { (SD) }\end{array}$ & $\begin{array}{l}\text { Post-test } \\
\text { Mean (SD) }\end{array}$ & t-test & P value \\
\hline & & $22.12(6.96)$ & $33.0(6.82)$ & 14.26 & $<0.001$ \\
\hline
\end{tabular}

${ }^{*} \mathrm{X}^{2:}$ Chi Square or Fisher's Exact Test

Table 3. Relationship of Subjects' Skills and Competencies Regarding Entral Feeding Care of Pre and Post Providing Educational Program

\begin{tabular}{|c|c|c|c|c|}
\hline $\begin{array}{l}\text { Subjects' Skills and Competencies } \\
\text { regarding Entral Feeding }\end{array}$ & $\begin{array}{l}\text { Pre-test N=94 } \\
\text { Mean }( \pm \text { SD) }\end{array}$ & $\begin{array}{c}\text { Post-test N=78 } \\
\text { Mean }( \pm \text { SD })\end{array}$ & t-test & $\mathbf{P}$-value \\
\hline \begin{tabular}{l|l} 
& $\begin{array}{l}\text { Subjects' skills and competencies } \\
1 .\end{array}$ \\
for pre-procedure
\end{tabular} & $6.38( \pm 1.74)$ & $10.60( \pm 1.73)$ & 89.7 & $<0.001$ \\
\hline $\begin{array}{l}\text { Subjects' skills and competencies } \\
\text { for during-procedure }\end{array}$ & $5.96( \pm 0.76)$ & $8.18( \pm 0.83)$ & 47.1 & $<0.001$ \\
\hline $\begin{array}{l}\text { Subjects' skills and competencies } \\
\text { for post-procedure }\end{array}$ & $5.28( \pm 0.82)$ & $7.50( \pm 0.88)$ & 47.4 & $<0.001$ \\
\hline $\begin{array}{l}\text { Total score of subjects' skills and } \\
\text { competencies of entral feeding care for all } \\
\text { procedure's stages (whole checklist) }\end{array}$ & $17.63( \pm 2.27)$ & $25.83( \pm 2.21)$ & 178.3 & $<0.001$ \\
\hline
\end{tabular}

Table 4: Correlation between nurses' knowledge and their skills about entral feeding care in period of pre and post providing of health education program

\begin{tabular}{|c|c|c|c|c|c|}
\hline Variables & Statistics & $\begin{array}{r}\text { Subjects' } \\
\text { knowledge about } \\
\text { entral feeding } \\
\text { care: before } \\
\text { education } \\
\text { program }\end{array}$ & $\begin{array}{r}\text { Subjects' } \\
\text { knowledge } \\
\text { about entral } \\
\text { feeding care: } \\
\text { after education } \\
\text { program }\end{array}$ & $\begin{array}{r}\text { Subjects' skills } \\
\text { and } \\
\text { competencies } \\
\text { regarding entral } \\
\text { feeding care: } \\
\text { before education } \\
\text { program }\end{array}$ & $\begin{array}{l}\text { Subjects' skills } \\
\text { and } \\
\text { competencies } \\
\text { regarding entral } \\
\text { feeding care: } \\
\text { after education } \\
\text { program }\end{array}$ \\
\hline \multirow{3}{*}{$\begin{array}{l}\text { Subjects' knowledge about } \\
\text { entral feeding care: before } \\
\text { education program }\end{array}$} & $\begin{array}{c}\text { Pearson } \\
\text { Correlation }\end{array}$ & 1 & 0.41 & -0.07 & 0.004 \\
\hline & $\mathrm{p}$ - value & & $<0.001$ & 0.46 & 0.97 \\
\hline & $\mathrm{N}$ & 144 & 96 & 104 & 78 \\
\hline \multirow{3}{*}{$\begin{array}{l}\text { Subjects' knowledge about } \\
\text { entral feeding care: after } \\
\text { education program }\end{array}$} & $\begin{array}{c}\text { Pearson } \\
\text { Correlation }\end{array}$ & 0.41 & 1 & -0.16 & 0.17 \\
\hline & $\mathrm{p}-$ value & $<0.001$ & & 0.12 & 0.15 \\
\hline & $\mathrm{N}$ & 96 & 96 & 96 & 78 \\
\hline \multirow{2}{*}{$\begin{array}{l}\text { Subjects' skills and } \\
\text { competencies regarding } \\
\text { entral feeding care: before }\end{array}$} & $\begin{array}{c}\text { Pearson } \\
\text { Correlation }\end{array}$ & -0.07 & -0.16 & 1 & 0.98 \\
\hline & $\mathrm{p}$ - value & 0.46 & 0.12 & & $<0.001$ \\
\hline
\end{tabular}


Impact of Implementing an Educational Program Regarding Care of Nasogastric Tube Feeding on ..

\begin{tabular}{|l|c|c|c|c|c|}
\hline education program & $\mathrm{N}$ & 104 & 96 & 104 & 0.98 \\
\\
$\begin{array}{l}\text { Subjects' skills and } \\
\text { competencies regarding } \\
\text { entral feeding care: after } \\
\text { education program }\end{array}$ & $\begin{array}{c}\text { Pearson } \\
\text { Correlation }\end{array}$ & 0.004 & 0.17 & 1 \\
\cline { 2 - 6 } & $\mathrm{p}-$ value & 0.97 & 0.15 & $<\mathbf{0 . 0 0 1}$ & \\
\cline { 2 - 7 } & $\mathrm{N}$ & 78 & 78 & 78 & 78 \\
\hline
\end{tabular}

\section{Regarding Sociodemographic characteristics:}

At the beginning of data collection, the researchers distributed 175 questionnaires. Before providing educational program about enteral feeding care, a total of 145 (82.8\%) completed the self - report questionnaire of nurses' knowledge of entral feeding care. And 104 nurses in different medical-surgical departments were assessed their skills and competencies about nasogastric tube insertion, administration of entral feeding, and care of patients post procedure. After providing those nurses educational program about enteral feeding care, a total of 96 of those nurses were re-completed the nurses' knowledge of entral feeding care and 78 of them were re-assessed about their competencies of entral feeding care skills (Table 1).

Table 1 showed that the most of the subjects were age between 22 and 28 years old (67.7\%), female $(81.3 \%)$, married $(55.2 \%)$, bachelor degree holders (97.9\%), Saudis $(55.2 \%)$, worked in different surgical departments $(88.5 \%)$, and had 1-5 years experience as staff (registered) nurse $(52.1 \%)$ and $(53.1 \%)$.

\section{Nurse's knowledge related to NGT Feeding:}

Chi square or fisher's exact tests were done to identify the relationship between subjects' knowledge about caring of patients with entral feeding tube pre and post providing educational program (Table 2). The findings of these analyses showed that there were significant differences between pre and post tests for total score of nurse' knowledge about entral feeding care and for all sub-scales of this questionnaire. The finding of these finding indicated that providing health education programs for nurses significantly improved subjects knowledge about 1) entral feeding care including: 1) definition $\left(\mathrm{X}^{2}=9.6\right.$, $\mathrm{p}$ - value $\left.\left.=0.005\right), 2\right)$ indication and advantages $\left(\mathrm{X}^{2}=18.7, \mathrm{p}\right.$ - value $\left.=<0.001\right)$ and 3$)$ contraindication $\left(\mathrm{X}^{2}=19.9\right.$, $\mathrm{p}$ - value $\left.=<0.001\right)$ of entral feeding, 4) insertion and removal of enteral feeding tubes $\left(X^{2}=35.0\right.$, $p$ - value $\left.\left.=<0.001\right), 5\right)$ confirming correct tube position $\left(\mathrm{X}^{2}=11.85\right.$, $\mathrm{p}$ - value $\left.\left.=<0.001\right), 6\right)$ types of TPN solutions and formulas' handling $\left(\mathrm{X}^{2}=10.7\right.$, $\mathrm{p}$ value $=<0.001), 7)$ enteral feeding, fluids and medications safely $\left(\mathrm{X}^{2}=24.1\right.$, p- value $\left.\left.=<0.001\right), 8\right)$ care of patients with enteral feeding tubes $\left(X^{2}=27.6\right.$, p- value $\left.=<0.001\right)$, 9) complications and disadvantages of enteral feeding $\left(X^{2}=29.5, \mathrm{p}\right.$ - value $\left.\left.=<0.001\right), 10\right)$ and nursing process related to enteral feeding $\left(\mathrm{X}^{2}=35.2\right.$, $\mathrm{p}$ - value $=<0.001)$. Moreover, the provided health education program significantly improved the total knowledge about entral feeding care $(t=14.26$, $\mathrm{p}$-value $=<0.001)$. About $91 \%$ of the subjects had satisfied knowledge about entral feeding care after they provided educational program, comparing to $62.5 \%$ of them had satisfied knowledge before this educational program (Table 2).

\section{Nurse's practices related to NGT Feeding:}

Paired t-test analysis was run to assess the relationship of subjects' skills and competencies regarding entral feeding care of both of pre and post providing educational program. The findings of this analysis showed that the provided health education program for nurses was significantly improved: 1) the subjects' skills and competencies for pre-procedure (mean $=10.60, \mathrm{SD}= \pm 1.73$ ) comparing to subjects' skills for pre-procedure before education program (mean $=6.38, \mathrm{SD}= \pm 1.74) ;(\mathrm{t}=89.7, \mathrm{p}=<0.001), 2)$ subjects' skills and competencies for during-procedure (mean $=8.18, \mathrm{SD}= \pm 0.83$ ) comparing to subjects' skills for duringprocedure before education program (mean $=5.96, \mathrm{SD}= \pm 0.76) ;(\mathrm{t}=47.1, \mathrm{p}=<0.001)$, and 3 ) the subjects' skills and competencies for post-procedure (mean $=7.50, \mathrm{SD}= \pm 0.88$ ) comparing to subjects' skills for preprocedure before education program (mean $=5.28, \mathrm{SD}= \pm 0.82) ;(\mathrm{t}=47.4, \mathrm{p}=<0.001)$ of entral feeding care. Moreover, there was a significant difference in the total scores for subjects' skills and competences of all steps of entral feeding care checklist after education program (mean $=25.83, \mathrm{SD}= \pm 2.21$ ) and before education program $($ mean $=17.63, \mathrm{SD}= \pm 2.27) ; \mathrm{t}=178.3, \mathrm{p}=<0.001$.

\section{*Relation between nurse's knowledge scores and practice scores regarding to NGT:}

A Pearson's correlation analysis was done to identify the relationship between nurses' knowledge and their skills about entral feeding care in period of pre and post providing them health education program. The finding of this study showed that there was significant, moderate and positive correlation between subjects' knowledge before providing them education program about entral feeding care and their knowledge after health education program $(\mathrm{r}=0.41, \mathrm{~N}=96, \mathrm{p}<0.001)$, and there was significant, very strong and positive correlation between subjects' skills before providing them education program about entral feeding care and their skills after education program $(\mathrm{r}=0.98, \mathrm{~N}=78, \mathrm{p}<0.001)$.

\section{Discussion}




\section{Regarding Sociodemographic characteristics:}

Findings of the present study indicated that more than half of nurses their age from 22-28 years old almost of them were baccalaureate degree (97.9\%) and had from 1-5 years nursing experience. This might be due to almost of nurses were newly graduates and working together at medical and surgical departments.This agree with Simpson, et al, (2014) who studied " The effectiveness of an educational intervention in changing nursing practice and preventing catheter related infection for patients receiving total parenteral nutrition ". Revealed that, the age range of most nurses was between 18 to 35years old (mean $=28$ ). In Contradiction to these findings also, Simpson, et al, (2014) who demonstrated that the educational level of the studied sample was nursing high school diploma program graduates $(6.7 \%)$, associate degree program graduates $(50 \%)$, and baccalaureate degree program graduates $(43.3 \%)$.

Regarding the gender of the participants, the results of the study declared that $81.3 \%$ of the study sample was female nurses. This high proportion of female nurses is most probably attributes to the fact that the study of BSN in the Saudi universities was exclusive for females only till few years ago, so the profession of nursing in Saudi Arabia was mostly feminine.

\section{Nurses' knowledge related to administration of total parental nutrition:}

Finding of the present study revealed that more than third of the studied sample $(62 \%)$ had unsatisfactory knowledge scores related to NGT, while more than half (38\%) of the studied sample had satisfactory knowledge scores. In agreement of these findings Simpson, et al, (2014) demonstrated that the mean score of nurses' knowledge about NGT was (22.12) before starting the educational program. This finding was consistent with their lack of knowledge prior to the educational intervention and failed to show any improvement. This reveals that the nurses' knowledge about enteral feeding in the different departments was low and inadequate. The results were Supporting to a study of William , et al, (2013) who assessed 253 critical care nurses from three major hospitals in Jordan; the results revealed that around $70 \%$ of the participants' scored less than $60 \%$ in knowledge comprehension regarding enteral nutrition.

Bartholomew, et al, (2013) who revealed that nasogastric intubation is an important modality in clinical practice. Although its safety and efficacy have been greatly improved through increased knowledge and skill, close patient monitoring and the specialized nutritional support teams were required. However the ease in which enteral feeding can now be provided, should be tempered by sound clinical judgment, in particular to avoid complications offering in the critically ill patient who may be intolerant. So the nurse should have broad base of nursing knowledge and practice to ensure that the benefits of enteral feeding outweigh the potential risks to any given patient are needed. The participants declared that the main reason behind the lack of knowledge about enteral feeding was the lack of hospital policies and protocols regarding enteral feeding management in the different departments which permits to any staff nurse to mange feeding patients with NGT, as well as lack of training programs, and work overload at word, were a participant causes in the shortage of knowledge.

\section{Nurses' practices related to administration of total parental nutrition:}

The study revealed that the Nurses at the medical and surgical departments King Fahd hospital had no available written protocols or resources of information to update their knowledge and improve their practices about enteral feeding, medications administration, drugs preparations, side effects, drug - drug and drug - food interactions. However, that may explain the level of nurses' knowledge and practices regarding enteral feeding. Relatively similar results were reported by Corpeleijn, et al, (2013) who concluded that the nursing practice regarding enteral feeding is not enough and highly reflected on the improvement of the patients' nutritional status and health condition, as well as, the patients' safety and reported medications errors in the different words.

This finding is supported by Delplanque, et al, (2015) who reported that The mean score of observations of nurses' practices with the control group before the in-service education was 45.7; the mean score afterwards was 66.5 . This improvement was statistically significant $(p<0.5)$. The current studies emphasized on increased nurse's practice related to entral feeding by naso gastric tube. With the increase in knowledge, development, and improvement in NGT feeding support, the provision of NGT feeding provides a comforting environment, and gives patients the freedom to return to normal activities. From this study, it is seen that nurses should be periodically evaluated to determine their level of knowledge and skill based on which appropriate educational programme can be planned Spain, et al, (2011).

In addition, this finding is agreed with Mota, et al, (2010). Who documented that nurses have important responsibilities in the care of patients who are receiving feeding by NGT, including pre- during post administration, hand washing before and after implementation phase. As well as Stechmiller, et al, (2011) in his study which entitled " A study to assess the effectiveness of structured teaching programme on care of patient with NGT among staff nurses in selected hospital of Bangalore" stated that the overall mean percent of pre test knowledge score was $67 \%$ and post test knowledge score was $87 \%$. The data further supports that post test 
knowledge scores were greater than the pre test knowledge scores. So, there is $20 \%$ enhancement in overall knowledge, and practice after the structured teaching program.

Relation between nurse's knowledge scores and practice scores regarding to NGT:

Findings of the present study reported that there is a positive correlation between nurse's knowledge and practice. This agrees with Shahin (2012) who stated that a highly statistical significant correlation between participants' scores of knowledge and practice in pre-program, post program, following the instructional program. This strong correlation between nurses' knowledge and practice is highly expectable; however, the effective establishment of enteral feeding is often hindered by lack of knowledge, basic knowledge about enteral feeding is essential for nursing practice. This result was congruent with a recent study which was about "the development of evidence-based guidelines and nurses' knowledge of enteral feeding".

The study found that several enteral feeding practices are directly influenced by nurses, and that practices suggests that nurses' knowledge related to enteral feeding is essential to achieve the best practice and optimal outcomes for patients (Bourgault et al., 2013).

\section{Conclusion}

The nurses' knowledge and practices regarding to naso gastric tube feeding at the medical and surgical departments were not enough with some unsafe practices. There was a lack of educational materials, policies and protocol about enteral feeding in the different departments. As well as a significant correlation were existed between their level of knowledge and practice. The educational program had a positive effect in improving the nurses' knowledge and practices regarding naso gastric tube feeding.

\section{Recommendations:}

\section{Based on results of the present study, the following can be recommended:}

It is recommended to establish a written updated protocol about nasogastric tube feeding to ensure enough knowledge, unified and safe nursing practice.

An education program based on evidence related to nasogastric tube feeding is of utmost importance for all nurses in different hospital department due to the shortage of new evidence-based knowledge and practices and the work overload on the nursing staff most of the time.

Nurse continuous education programs about enteral nutrition can play a part too in supporting clinical practice by placing a strong emphasis on theoretical concepts, skill development and the use of critical appraisal skills.

Enhancing collaboration between health care providers and offering appropriate counseling should also be emphasized because the quality and safety in relation to nutritional nursing care is dependent on the interactions between the nurse and patient, between, the nurse and the team, and the nurse and the organization.

\section{Acknowledgements}

I would like to thank Dr. Rami Azmi Elshatarat for helping me in data entry and analysis.

\section{References}

[1]. Lima, P.A.; Carvalho, M.; Costa, A.C.; Moreira, M.E. Variables associated with extra uterine growth restriction in very low birth weight infants. J. Pediatr. 2014, 90, 22-27. [CrossRef] [PubMed].

[2]. Decloedt, E., \& Maartens, G. (2011). Pit falls of administering drugs via nasogastric tubes. SAMJ: South African Medical Journal , 99 (3), 148-149.

[3]. Ismail, M. S. (2010). Impact of A Suggested Teaching Protocol Upon Nurses' Knowledge and Practices About Drug-Nutrient Interactions Among Critically Ill Patients. Egyption journal of medical science, 27 (2), 23-29.

[4]. Loys, C.M.; Maucort-Boulch, D.; Guy, B.; Putet, G.; Picaud, J.C.; Hays, S. Extremely ill: How neonatal intensive care unit teams can reduce postnatal malnutrition and prevent growth retardation. Acta Paediatr. 2013, 102, 242-248. [CrossRef] [PubMed].

[5]. Dutta, S.; Singh, B.; Chessell, L.; Wilson, J.; Janes, M.; McDonald, K.; Shahid, S.; Gardner, V.A.; Hjartarson, A.; Purcha, M.; et al. Guidelines for feeding . Nutrients ,2015, 7, 423-442. [CrossRef] [PubMed].

[6]. Persenius, M., Hall-Loard, M., Baath, C., \& Larsson, B. (2014). Assessment and Documentation of Patients Nutritional Status: Perception of Registered Nurses and Thier Chief Nurses. Journal of Clinical Nursing, 17, 2125-2136.

[7]. Schmidt, N. A., \& Brown, J. M. (2012). Evidence-Based Practice for Nurses: Appraisal and Application Research. Canada: Jones \& Bartlett Learning International.

[8]. European Medicines Agency. Available online: http://www.ema.europa.eu/docs/en_GB/document library/Scientific_guideline/2009/09/WC500003754.pdf (accessed on 27 July 2015).

[9]. Shahin, M. (2012). Impact of a Designed Instructional Program about Enteral Nutrition on the Nurses' Knowledge and Practices at the Critical Care Department of Al-Manial University Hospital. Cairo: Faculty of Nursing - Cairo University.

[10]. Sivakumar, A. and Haigh, A. (2012) Implementing evidence-based practice (or best possible practice) through protocols in an accident and emergency Dep. in Brent \& Harrow. In Implementing Evidence-based Changes in Healthcare(Eds, Evans, D. and Haines, A.) Radcliffe Medical Press, Oxon.

[11]. Zhu, L., \& Zhou, Q. (2013). Therapeutic concerns when oral medications are administered nasogastrically. Journal of Clinical Pharmacy and Theraputics , 11, 11-14

[12]. Singer, P., Berger, M. M., Berghe, G., Biolo, G., Calder, P., Forbes, A., Griffiths, R. D., Kreyman, G., Leverve, X. and Pichard, C. (2011) ESPEN Guidelines on Parenteral Nutrition: Intensive care. Clinical Nutrition, 28, 387-400.

[13]. Persenius, M. W., Larsson, B.W. \& Hall-Lord, M. L. (2009).To have and to hold nutritional control: Balancing between individual and routine care. A grounded theory study. Intensive and Critical Care Nursing, 25,155-162. doi:10.1016/j.iccn.2009.03.002. 
[14]. Behara, A. S., Peterson, S. J., Chen, Y., Butsch, J., Lateef, 0., \& Komanduri, S. (2011). Nutrition support in the critically ill. A physician survey. Journal of Parenteral and Enteral Nutrition, 32(2),113-119. Retrieved March 9, 2012, from http://pen.sagepub.com.

[15]. Marshall, A (2014). Information use in clinical practice: A case study of critical care nurses' enteral feeding decisions. (Doctoral dissertation, The University of Sydney 2008), Sydney, Australia.

[16]. Simpson, M. R., Stevens, P. and Kovach, C. R. (2014) Nurses' experience with the clinical application of a research-based nursing protocol in a long-term care setting. Journal of Clinical Nursing, 16(6), 1021-1028.

[17]. William, T. A. \& Leslie, G. D. (2013). A review of nursing care of enteral feeding tubes in critically ill adults: Part 1. Intensive and Critical Care Nursing, 20 (6), 330-343. doi:10.1016/j.iccn.

[18]. Bartholomew, J.; Martin, C.R.; Allred, E.; Chen, M.L.; Ehrenkranz, R.A.; Dammann, O.;

[19]. Leviton, A. Risk factors and correlates of velocity in extremely newborns: The elgan study. Neonatology 2013, 104, $298-304$. [CrossRef] [PubMed].

[20]. Corpeleijn, W.E.; Kouwenhoven, S.M.; van Goudoever, J.B. Optimal growth of adults. World Rev. Nutr. Diet. 2013, 106, $149-155$. [PubMed].

[21]. Delplanque, B.; Gibson, R.; Koletzko, B.; Lapillonne, A.; Strandvik, B. Lipid quality nutrition: Current knowledge and future opportunities. J. Pediatr. Gastroenterol. Nutr. 2015, 61, 8-17. [CrossRef] [PubMed]

[22]. Spain, D., McClave, S., Sexton, L., Adams, J., Blanford, B., Sullins, M., Owens, N. and Snider, H. (2011) Infusion Protocol Improves Delivery of Enteral Tube Feeding in the Critical Care Unit. Journal of Parenteral and Enteral Nutrition, 23(5), 288-298.

[23]. Mota, M., Barbosa, I., Studart, R., Melo, E., Lima, F., \& Mariano, F. (2010). Evaluation of Intensives- Nurses' Knowledge Concerning Medication Administration Through Nasogastric and Enteral Tubes. Ref Latino-Am Enfermagem , 888-894.

[24]. Stechmiller, J. K., Treloar, D. and Allen, N. (2011) Gut dysfunction in critically ill patients: a review of the literature. American Journal of Critical Care, 6 (3), 204-9.

[25]. Bourgault, A. M., Ipe, L., Weaver, J., Swartz, S., \& O’Dea, P. J. (2013). Development of Evidence-Based Guidelines and Critical Care Nurses’ Knowledge of Enteral Feeding. Critical care nurse, 27 (4), 17-29. 